\title{
When Explanations “Cause” Error: A Look at Representations and Compressions
}

by

Michael R. Lissack

\begin{abstract}
:
We depend upon explanation in order to "make sense" out of our world. And, making sense is all the more important when dealing with change. But, what happens if our explanations are wrong? This question is examined with respect to two types of explanatory model. Models based on labels and categories we shall refer to as "representations." More complex models involving stories, multiple algorithms, rules of thumb, questions, ambiguity we shall refer to as "compressions." Both compressions and representations are reductions. But representations are far more reductive than compressions. Representations can be treated as a set of defined meanings - coherence with regard to a representation is the degree of fidelity between the item in question and the definition of the representation, of the label. By contrast, compressions contain enough degrees of freedom and ambiguity to allow us to make internal predictions so that we may determine our potential actions in the possibility space. Compressions are explanatory via mechanism. Representations are explanatory via category. Managers are often confusing their evocation of a representation (category inclusion) as the creation of a context of compression (description of mechanism). When this type of explanatory error occurs, more errors follow. In the drive for efficiency such substitutions are all too often proclaimed - at the manager's peril.
\end{abstract}

\section{Introduction}

Simple models can be many a manager's undoing. Models based on labels and categories we shall refer to as "representations." More complex models involving stories, multiple algorithms, rules of thumb, questions, ambiguity we shall refer to as "compressions." Representations have little capacity for dealing with complexity. In the assertion of category as explanation, context is all too often ignored. Yet, context is key to any understanding of the mechanisms of change. The manager's use of a simple representation can thus mask much of what might be important regarding change. In that masking lies the potential for grave error. This potential is revealed through the study of what is known as "complexity."

Complexity is the study of effects which occur "with weaving" (com-plex). It is to be contrasted with the merely complicated (com-plic meaning "with folds"). While the complicated can be unfolded for analysis, the complex cannot. The study of complexity is concerned among other things, with: interrelatedness, ambiguity, emergence, the notion of multiple levels and perspectives, and paying attention to weak in addition to strong signals. Complexity is usually portrayed as an enemy of both efficiency and coherence. Many management texts are devoted to the reduction of complexity. Still others suggest that complexity is "reduced" by being embraced." JC Spender notes: "the degree of complexity present is the extent to which our efforts at reduction have failed." (Letiche \& Lissack, 2011) In truth we do not go through life overwhelmed by the apparent complexity continually confronting us. Instead we make choices about what to deal with, what to see, and what questions to ask. We choose to explain via category or via mechanism. We choose to assert the simple over the complex. And then we act.

What the assertion of simplicity (and simple representational models of explanation) offers is an expression of coherence-of making sense. Managers are trained to act on simplicity, but that 
simplicity is opposite to the complexity of the world in which such businesses operate. When we perceive the world as coherent, as holding together and as making sense, we have the ability to assume our situation, and 'to get on with things'. Both complexity and simplicity offer paths to success - but those paths are very different. Complexity threatens the managers' notion of coherence. When our perception of coherence is shattered; the world no longer seems to hold together. Things do not make sense. We continually have to ask questions and we worry about our inability to find answers in which we can believe. We react to our loss of assurance with a loss of self-confidence; we pull back to whatever coherence we can find.

We make sense of the world through explanation. Retrospective explanation is then used as the basis for prediction, and upon such prediction we act. But, as noted in the Wall Street Journal, "We are ruined by our own biases. When making decisions, we see what we want, ignore probabilities, and minimize risks that uproot our hopes." Our minds dislike ambiguity and doubt. Instead we have an ingrained desire to construct coherent narratives which, the noted economist Daniel Khanamen asserts, leads us to seek confirming evidence, while disregarding information that refutes our prior view. What results is a confidence in our understanding which is greater than the circumstances warrant. So what happens when our explanation is wrong? Let us illustrate by example.

\section{Efficiency versus Resilience}

Consider two examples from the current era: the mortgage finance mess and the level of rancor in American politics. The former takes as a root cause two simple ideas: more ownership is beer for a society and housing prices always go up. These ideas then became the basis upon which both government regulatory philosophy and private business models were constructed. For more than twenty years, the ideas, the models and the regulations all supported one another in a regime of positive feedback (much like the stories of Bernie Madoff's financial acumen) which ultimately became a burst bubble. More is not always better it seems and prices do not always go up. As for politics in America, the practice of labeling one's opponents as "evil" and "less than human" as a substitute for actually engaging in policy debate hit its crescendo with the nomination of Sarah Palin and the shooting of Congresswoman Gabby Giffords. Labels are simple. Evil is easy to grasp as a concept. The ramifications of that ease are not only a loss of meaningful policy debate but also violence and fear. Thus the simple representation (housing prices always go up and our opponents are evil) serves as an explanation which then fuels an ever expanding cycle of decisions actions and when challenged reversions back to the original simple explanation.

Simple representational explanations have the virtue of efficiency. Our "modern" world has found great efficiencies in the ascribed coherence of rules and algorithms. Attributing cause to category is a principle of least action. Efficiency has its place but it also has its price. Like anything else, too much of a good thing can prove to have ugly consequences. Efficiency thrives on simplicity and it struggles when beset by complexity. As businesses and organizations face an ever more complex and rapidly changing world, complexity is its most common factor and resilience in light of that complexity is the key to survival. When simple explanations are wrong then the decisions based on them are likely to also be wrong. There is also unlikely to be a reservoir of yet other explanations and decisions to take the place of the now shown to wrong ones (since it was more "efficient" to discard such a reservoir as unnecessary and expensive.) Yet, without the reservoir of "other ideas", the organizations ability to find correct explanations and make subsequent correct decisions is challenged. Efficiency it seems can be the enemy of resilience. 
For the purposes of this chapter, we note that simplicity is often expressed in the tendency of managers to assert labels (representation) instead of defining models (compression) and to identify best practices (representation) rather than explore affordances (Gibson, 1977, 1979, McGrenere \& Ho, 2000) (the adjacent possibles of their context, Kauffman, 2002). The mistake is one of (ascribing a label) attributing cause to category when identity is undetermined, uncertain and undefined (which instead suggests a need to identify mechanism and exposes the reality that the representation is likely to be inadequate). Only if one has well-earned confidence in one's descriptors does it make sense to use them to analyze a situation. Metaphors and analogies may be fascinating and tantalizing, but they are very uncertain and questionable. If one wants to 'model' a situation one needs to be sure of the definitions, identities and terms of use one is making use of. And if one wishes to assert that a representation holds true for a given situation, one must attempt to match the context of the representation to the situation actually at hand. No such epistemic care is normal in business. Labels are all too quickly assumed to be accurate depictions of reality. The complexity reduction method is to substitute an indexical (a placeholder) where either casual model or context demands an individual. Such a casual reference to indexicals -- in situations where the models and their use demand individuals (i.e. situatedness and context dependence) -- results in the replacement of a strong homological relationship with a weaker analogical one. It is this replacement - of compressions with representations -- which this chapter calls into question.

Management scholars, consultants, and "gurus" further compound the confusion by claiming that such indexical representations (e.g. a canonical best practice) can be used instead of experiments on the real world - i.e. that the evocation of the indexical is "better" than experimenting with constructing a context specific individual. Organizational users of indexicals often assert accuracy where it cannot be shown and may not exist. So, though the provisionality and contingency of all models is well-known, popular culture persists in utilizing the special case of representations as if they were more than they are. In effect, category attributions are given a power they do not deserve. If we need a way of reducing the world enough that we can cope with it and act in it, then the use of labels helps people to have an actionable view of the world. Labels play a very valuable role in limiting the complexity. Instead of discussing multiplicity (embodied by compressions), the simplicity of a crude model and a few labels (in the form of representations) is often preferred.

Representations by managers often take the form of rule based checklists and of Demming inspired statistical controls both of which assume that the labels and underlying models have permanent validity. A stasis to the world is assumed which seldom exists. Such a stasis assumes that affordances are predictable, context is controllable, and emergence is nonexistent. The world of practicing managers does not match these oversimplifications. Prediction, at best, is only possible in the short term. Boundaries are always shifting. The composition of work teams, temporary organization, the company, the industry, or the competitive environment, is rarely predictable (in the long term at least). Identities are unclear. The tradeoff between outcome and process does not favor one over the other. In the world we live in, emergence is pervasive, context is seldom controllable, ecologies are emergent and few affordances are predictable. Situation and context play key roles. In the complex world of organization, continuity is but a fragile, temporary and illusionary notion; the assumption of predictability does not hold.

Keeping with our examples of mortgages and politics, consider the strange concept of a "nodocumentation loan." When these loans started in the 1970's they were being made to those who owned their own business (and thus whose cash flow - the money available to repay a loan 
- might be very different from their income - the tax records which include lots of non-cash expenses), and other prospective borrowers who did not receive the paperwork associate with being a salaried employee. This group of borrowers had, over time, developed a BETTER repayment record than normal salaried borrowers. If one allowed the detailed explanation of "we need to know the borrower better because we have less documentation" to explain, then the future problem might not have occurred. But instead the simple explanation of "no-docs perform better than regular docs" was allowed to take hold. This explanation predicted safety in such loans and when couple with the belief that "prices always go up" made the loans seem very reliable. Reliably open for exploitation by those who felt little need to write down the truth. Some $20 \%$ of the problem mortgages reported in 2010 were liars' loans. So much for predictability. In politics can one really predict the position of a politician on whom the label "evil" has been attached?

By making assumptions (and in so doing restricting ourselves to a set of labels and a model) we predetermine what might be learned, which will limit the options that appear to be open to us. This is because by adopting a particular perspective, and therefore making assumptions consistent with that perspective, we limit what we can 'see'. "We often fail to allow for the possibility that evidence that should be critical to our judgment is missing. What we see is all there is." (Khneman, 2011) The perspective acts as a lens that only allows particular features to come into focus -- all other features are lost or assumed not to be relevant. Furthermore, in communicating with others, by making use of a particular viewpoint, we limit our and their ability to 'see' what is relevant. The problem with ascribing a label, and using it as your method of explanation, is that once one has ascribed it, once one has said this belongs to Label $\mathrm{X}$, then the explanation is done. The assertion is that the representation holds. Implicitly it is further asserted that the complexity and degrees of freedom found in compressions are unnecessary. "I am a "nice" person. Nice persons do X. I must do X." There is no room in this equation for context. The representation is assumed to govern.

What the focus on representations ignores, is that there are two kinds of coherence in the world. Ascribed, measured coherence focuses on how well a given item, person, situation etc. matches the assigned label. It also examines how well rule ' $x$ ' matches desired outcome ' $y$ '. The underlying assumption is that the pairing of label ' $x$ ' and rule ' $x$ ' will produce desired outcome ' $y$ '. But, label based rules are not the only kind of explanatory coherence available to us. The traditional craftsman's apprentice spends years observing the master at work with two objectives: to gain awareness of what is contextually possible and to develop a repertoire of activities to make use of those possibilities. Aircraft pilots undergo hundreds if not thousands of hours of (simulation) training with much the same objective -- though their task is to recognize dangers that may present themselves context by context, and to develop a repertoire of reactions to these dangers. Both the craftsman's apprentice and the pilot do not learn their skill from the study of label-based rules. Instead they are required to engage with experience and to learn from context. In a recent work (Letiche and Lissack, 2011) Hugo Letiche and I call this experienced coherence. While representations may suffice in situations where retrospective ascribed coherence is the standard, they pose significant risks in those other situations which call for experienced coherence.

Table 1 below illustrates the implications of these two kinds of explanatory coherence seeking behaviors - ascribed coherence (agreement with label) and emergent or experienced coherence (agreement with present context). As you make your way through the table please note the contrasts between the types of explanation evoked by the two types of coherence, Representations and ascriptions work best in a static world and are challenged by the possibility 
of change. Compressions and experience, by contrast, evoke degrees of freedom necessary to allow for change and emergence to be accommodated.

\begin{tabular}{|l|l|l|}
\hline Characteristic & $\begin{array}{l}\text { Ascribed Coherence } \\
\text { (Agreement with Label) }\end{array}$ & $\begin{array}{l}\text { Emergent Coherence } \\
\text { (Agreement with Present } \\
\text { Context) }\end{array}$ \\
\hline Reaction to “Many" & Complicated - unfold & $\begin{array}{l}\text { Complex } \\
\text { weave }\end{array}$ \\
\hline See Pattern & Provide a Label & Observe Affordance \\
\hline Adjacent Possibles & Predict & Explore \\
\hline Weak Signals & Reject as Noise & $\begin{array}{l}\text { Investigate } \\
\text { Resonance }\end{array}$ \\
\hline Multiple Signals & Frame/ Bracket & Dialogue Amongst \\
\hline Multiple tasks/roles & Compartmentalize/deny & $\begin{array}{l}\text { Awareness of active role } \\
\text { playing }\end{array}$ \\
\hline Role in a Conversation & Speak & Listen \\
\hline Tone in Conversation & State Facts & Ask Questions \\
\hline Focus of Efforts & Efficiency & Resilience, Creativity \\
\hline Inspiration & Machine & Monologue \\
\hline Type of Speech Act & Dialogue \\
\hline
\end{tabular}

Table 1

When we use representations, labels, categories, and codes we have a tendency to demand coherence (a unity or oneness) between the situation, people, process etc. to which we are applying the representation and our understanding of the meaning of the representation itself. (That demand for coherence is the focus of the much of the literature on the subject c.f. Thagard, 1992, 2000.) When we observe a mismatch between our understanding of the representation and the target of our use we seek to demand a correction (more on this below when we discuss the Mori Uncanny Valley, Mori, 1970, 1982). Ascribed coherence and experienced coherence describe very different kinds of "matches" and "mismatches."

It is this type of mismatch which explains the New York City police raid on the Fook On Sing Funeral Supplies in August, 2011 (Singer and Kilgannon, 2011). Fook On Sing Funeral Supplies is a well-known Chinatown establishment where members of the Chinese community go to acquire expertly crafted paper replicas of items which where symbolically important to their 
recently departed. The paper replicas are burned on the funeral pyre. At no time would they be used as if they were a substitute for the real item. Yet on that fine August day, Wing Sun Mak the proprietor of Fook On Sing Funeral Supplies was arrested for selling counterfeit Louis Vuitton handbags. Paper counterfeits. To be burned at the cremation of the dead. Because they were after all counterfeits. Yes the label - the representation - fit. But the compression, the story and its context did not. Ascriptive coherence suggested that the paper hand bags were contraband. Experienced coherence told a very different story.

Managers make this kind of error far more often than the police. When the focus is on efficiency, in order to assure coherence, we create lists and provide codes that keep us tied to the ascribed meanings. We sanitize out the ambiguous and the unexpected. We look for confirming evidence and eliminate outliers as "noise." Indeed, there are times when efficiency and strict adherence to codes and checklists are absolutely essential. We want the products we order to arrive on time with excellent quality. We want our computers to operate without the need for error messages, and our baggage to arrive at the same airport and time as we do. If efficient codes have produced a positive experience before, we may want the next experience to be just like the previous one. Measured coherence and the establishment of procedure to enforce it are integral to how much of our world operates.

But being prepared for emergent possibilities is not simply a matter of making sure that we've checked our lists, and we've checked them twice. It requires organizations open to experience, prepared for the unpredictable, both in operational mindset and resource allocation. It also requires us to not ignore or dismiss that emergence will and does happen, based on the simple reasoning that we can only recognize change in hindsight. The New York police simply had no category for the "counterfeits" of Fook On Sing Funeral Supplies. Many managers have limited ability or resources to tweak "best practice" for local conditions. In both cases, the generic indexical label (the representation) is allowed to explain and thus cause behavior. These differences were shown above in Table 1 - as the difference between the ascribed coherence of representations (with few degrees of freedom) and the experiential coherence of compressions (with several degrees more).

\section{The Risk}

The risk we face is that our explanations are wrong and so are the actions/decisions based upon them. Computers rely on efficiency's form of coherence. To a computer, coherence is the degree to which an item ' $x$ ' matches a definition or a set of items having observable qualities that match one another. Computer coherence is about measurement. Coherence of this kind is not created it is assigned, ascribed, and measured. This is the coherence of efficiency. Efficiency has no room to consider context, history, and situation. Efficient coherence demands a context of stability. The more complex experienced coherence entails a process of finding stability in context. Without reliance on the former, efficiencies are difficult to create ad exploit. Without an awareness of the latter, life passes us by and crises descend seemingly from nowhere. Miracles happen when context history and situation combine in a fortuitous way; nasty surprises occur when context history and situation combine in an unfortunate way. In both cases, the predictions at the basis of efficiency's coherence, did not pan out. Housing prices did not keep going up. Making progress on political fronts sometimes requires splitting difference with those who are "evil." Fook On Sing Funeral Supplies made the New York police look foolish. 
We have to make assumptions; it is unavoidable. Nonetheless, it is important to appreciate the significance of doing so. When managers learn to rely on labels and simplistic encoding methods and singular decodings, they also learn to discount stories and emotions, which are not so easily described in term of rationality and linearity. When managers find that the world is best dealt with through compartmentalization or reductionism, they are tend to think that it is OK to deny the reality of interrelationships or of the multiplicity of interpretations that exist whenever situatedness is acknowledged. When managers learn that abstract quantitative models contain "truth," they are being taught that truth does not include individuality, weak signals, embodiment, or context. Managers learn these lessons not only in the MBA, but also continually in the "managerial environment" surrounding them when they are at work. Managers can find solace in simplistic business models that promise protection from unpredictability, and an excuse to not have to think.

Labels and categories eliminate the individual variations of specific items. The substitution of the label for the thing itself thus simplifies the world. Labels form a very valuable role in limiting the world. Instead of actively discussing the multiple approaches which may all be interpretations, enactments, decodings, or embodiments of a model, managers often act as if there is but one or perhaps two decodings. These "privileged" interpretations are given status as names, labels, or symbols -- and the labels are then used as guides for action.

Here is where the risk of using the wrong kind of explanation manifests itself as poor decisions and inappropriate actions. The language we each use to describe our surroundings predetermines what we 'see'. As Kuhn (1962) put it: "You don't see something until you have the right metaphor [model] to let you perceive it." Or as suggested by Srivastva and Barrett (1988), naming implies anticipations, expectations, and evaluations toward the named. By making assumptions (and in so doing restricting ourselves to a particular or one method of decoding) we predetermine what might be learnt, which will limit the options that appear to be open to us as managers. Indeed, one "normal" strategy for dealing with the complexity around us is to attempt to categorize what we encounter and to draw boundaries around what we are willing to "deal with." The rest we ignore. The act of boundary setting, like the act of categorizing, is one of brute force. Complexity is reduced with a will for (simple) sensemaking. Items, events, people, contexts, interactions are either 'in' or 'out'. At best, there are degrees of being 'in' or 'out'. Bureaucratic and industrial activity depends on boundaries and routines to exist. They are label-driven; their 'efficiency' requires boundary setting. Often the boundaries are defined in 'models' used to determine which label is to be placed onto which situation.

Managers --- taught by both academics and management consultants -- deal with the surfeit of information, complexity and anxiety, in their worlds by compartmentalizing and modeling: "If we can model it we can manage it." When managers say or think this, they tend to mean the application of either a business or a quantitative (computer) model. The very existence of the model is taken to mean that the model is appropriate for application. Do what the model says, and complexity will be reduced, and anxiety will be lessened. It is often blindly assumed that the models are correct, and that they somehow capture what is important for business decision making. In other words, we can apparently accept the model's reifications without concern. If, it were only that simple....

Explanations are the basis of the next decision and the next action. When managers "enact" the environment, Weick (1995) claims "they construct, rearrange, single out, and demolish many "objective" features of their surroundings ... they unrandomize variables, insert vestiges of orderliness, and literally create their own constraints." In other words, they attempt to reduce 
the "world" to their "model" and labels. But all too often management and its acolytes merely invent models and labels. The claim is made that the chosen labels and their underlying model(s) are useful for prediction and control. But unlike in hard science, control experiments are few and far between, and studies to "disprove" hypotheses are discouraged. "Truth" and "causality" are often proclaimed whenever correlation coefficients exceed 25 percent. Some might suggest that these shortcomings, in the eyes of hard scientists, demonstrate how poorly developed management science really is. However, we argue that the primary reason for these shortcomings is that organizations are simply not amenable to traditional scientific analysis. It is not that business scientists have applied their scientific tools badly (though this may also be the case); but that the tools used are simply not suited to the subject matter.

Synecdoche (yes a fancy word which is a part of speech) has become a managerial tool of which managers lack any awareness. A synecdoche is the use of a part to stand for a whole e.g. when one refers to a car as "wheels" or implicitly embodies an organization by the interactions with its representative. We use metaphors as synecdoche (relying on the mapping we make of similarities and ignoring the more complex arena of dis-similarity and context dependence.) Brands are perhaps our paradigmatic synecdoche as is the media's love of the sound bite and the Internet's love of the keyword. To be known by a Twitter is synecdoche. To be eliminated due to a six sigma evaluation is synecdoche. To make use of a belief in the "bell curve" or a "Gaussian distribution" in decision making is synecdoche. So too is labeling of politicians by a singular position they hold. So too was the simplistic belief in always rising housing prices. Synecdoche is in desperate need of being exposed. It is the hammer to the manager's love of nails. While the manager's tool kit holds more than synecdoche, synecdoche holds to its pre-eminence with the very lack of awareness of its existence.

Husserl (1900) warned of the dangers of such invisibility in his description of the fundierung relation. Fundierung is the invisibility we afford the pen as the instrument when we are focused on accomplishing the writing. We look past the "foundation" (fundierung) which affords the very activity we seek to accomplish. The danger lies in our reaction at those times when we are forced to overcome the fundierung relation and look explicitly at the medium of which we are making use (as when the pen runs out of ink). The success of the IPhone is due to fundierung (we can ignore the phone while making use of the apps) and the opposite (the very need to be aware of our interactions with the phone) describes much of Microsoft's problems in the marketplace. (Blackberries by this analysis found themselves in the middle - often with apps that afforded fundierung and yet demanding enough of attention to be recognized as "using a blackberry.")

The fundierung of synecdoche and of our use of representations is what gives rise to many a managerial challenge and to many a nasty surprise. Who would have thought that two obscure words could explain so much?

\section{The Mori Uncanny Valley and Its Effects}

Coherence theory (both that of truth and of Thagard) would suggest that as the number of identified common factors between two items increases so too would the recognition of "sameness" and mutual acceptance. This belief underlies the thought that one can "reason" one's way to mutual acceptance of a representation or a label. Yet, "the uncanny valley" of Japanese roboticist Masahiro Mori suggests that this is NOT always true. When one plots emotional response against similarity and claimed identity (see Figure 1), the curve is not a sure, steady upward trend (as indicated by the 45 degree sloping line). Instead, there is a peak shortly before one reaches a completely semblant "look" . . . but then a deep chasm plunges 
below neutrality into a strongly negative response before rebounding to a second peak where the claimed resemblance is complete. In its original form, describing robots, the uncanny valley:

"represents the point at which a person observing the creature or object in question sees something that is nearly human, but just enough off-kilter to seem eerie or disquieting. The first peak, moreover, is where that same individual would see something that is human enough to arouse some empathy, yet at the same time is clearly enough not human to avoid the sense of wrongness. The slope leading up to this first peak is a province of relative emotional detachment-affection, perhaps, but rarely more than that." (Bryant 2006)

The Mori Uncanny Valley

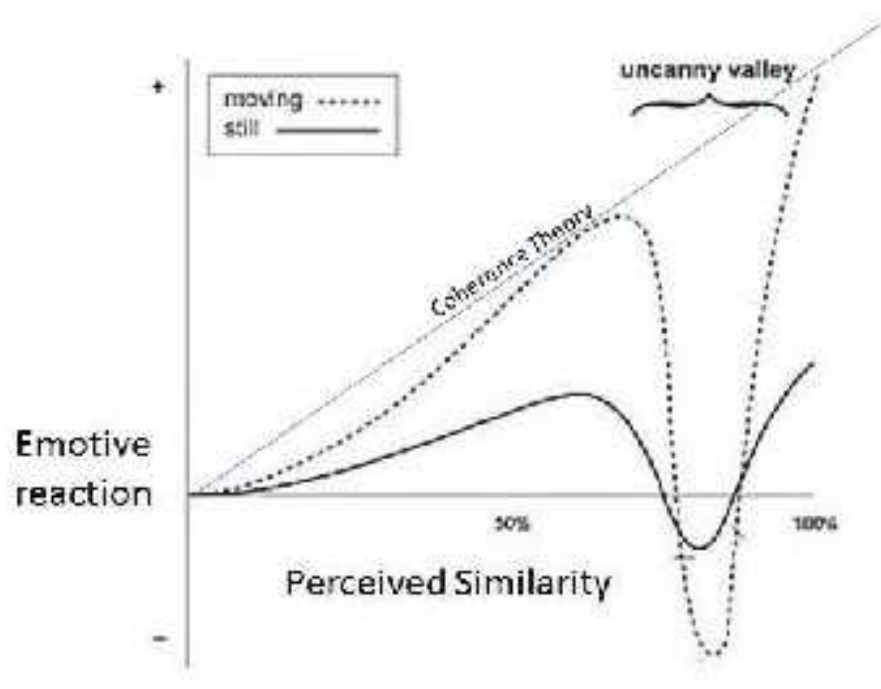

Figure 1. The Mori Uncanny Valley

To place this figure into present context - first there is engaged discussion, then as the overlap between terms with disassociative meanings becomes too great there is repulsion, finally when mechanism (explanations of actions and meanings not of labels) is allowed to assert itself the overlapping word choices are accepted as a means of bridging gaps or "boundary objects" (Star \& Griesemer 1989) and emotional coherence is regained. The valley occurs when the selfidentity of the observer is threatened by the use of a representation or label counter to that used by the observer. The threat seems to occur when the number of identified common factors (the reasoning used to demand adherence to a given representation) increases above the $50-60 \%$ level - assuming that the observer has another label/representation he uses to explain the same material. Another way to describe the valley is shown in Figure 2: 


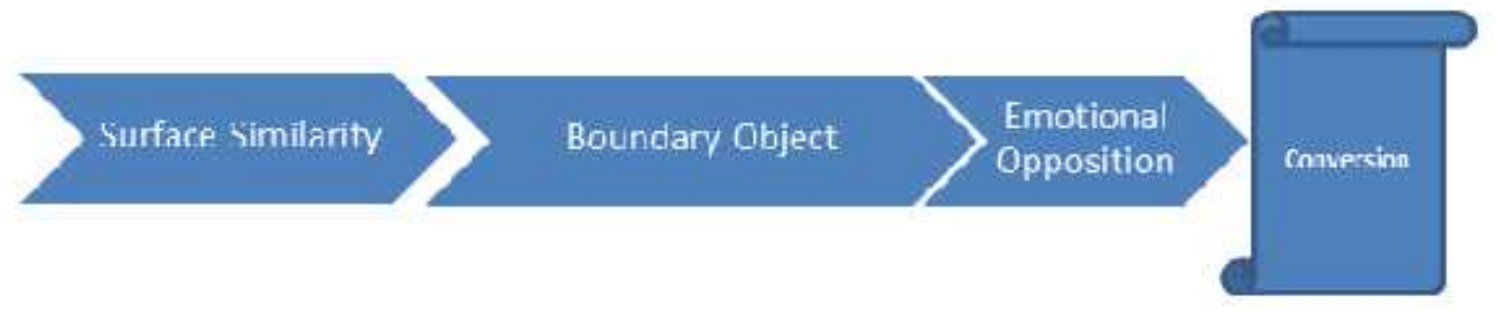

Figure 2: The Progression of "Acceptance" in the Mori Uncanny Valley

Given the existence of two labels (categories) to describe some item/event/context and the emotional attachment of the observer to the first label, as the perceived characteristics which fall into label \#2 increase the observer shifts his/her perception of that label from 1) surface similarities which only highlight differences to 2) boundary objects which give rise to explorations of metaphor to 3 ) emotional opposition which blocks "rational discussion" to finally a begrudging acceptance that perhaps label \#2 is a "better" fit.

The Mori Valley suggests: when a claim is made that a given representation applies to set of circumstances, situations, individuals, events etc. an observer may tend to react to that claim in a manner approximating Mori's curve. The use of a different label for a similar set of circumstances may evoke a significantly negative reaction. This is directly in contradiction to the claims of "boundary object" proponents who claim that the overlap allows for the identification of a common area between the two thoughts and that this common are becomes the basis for dialogue. While both the Mori hypothesis and the boundary object hypothesis can simultaneously be true where the perceived similarity is at or below the first Mori peak, the hypotheses diverge thereafter.

The Mori hypothesis suggests that once similarity crosses a threshold there is an emotive reaction which interferes with rational discourse. Surely this does not apply to everything; and common sense suggests that it applies only to items where the observer has either an emotional investment or has incorporated the representation of the item into self-identity. If true, then the ascription of an indexical representation to a seemingly "misfit" example of set would provoke the reaction. Think of it as a form of cognitive dissonance caused by too much similarity. It is this risk - emotional rejection from the use of the same signs, symbols, words, labels etc. for two meanings -- which demands awareness by managers.

When liars loans started being reported as a problem - worse when liars loans actually started being advertised by mortgage brokers as "liars loans" the Mori hypothesis explains some of the willingness of bankers and regulators to "look the other way." When Harry Markopolos was ignored by the SEC while complaining about Bernie Madoff, once again the Mori hypothesis provides a reasonable explanation. The Mori hypothesis asserts the primacy of an established relationship between representation and compression such that it becomes difficult to dislodge the mapping except upon extremely strong evidence. Kahneman and others have referred to this as a "confirmation bias" - our tendency to only take in evidence which confirms to our preestablished beliefs. That bias becomes almost intractable when combined with Mori valley style 
cognitive dissonance. "We are ruined by our own biases. When making decisions, we see what we want, ignore probabilities, and minimize risks that uproot our hopes." (Berman, 2012)

Inherent in the multiplicity of meanings is the recognition that only one meaning will be primary within the context of a given situated activity. That primary meaning will not be the solely representative meaning but will take its primacy from the context. Word choice in usage is tentative much as the acceptance of a theory. What works for the moment may be supervened by a better meaning in an instant. Activity shapes meanings, and access to meanings further influences potential activity. In theory, the dissonance produced thereby forces a reversion in the perceived meaning of the word. Context dependence takes over. "It is not merely the content of a word that changes, but the way reality is generated and reflected in a word"(Vygotsky, 1962). In practice, the Mori hypothesis suggests that stubbornness and defensiveness will kick in instead as defensive reactions to the threat posed to the dominance of the previously accepted representation or label.

Douglas Hofstadter (1995) has labeled this idea as "conceptual slippage." Such slippage would works as follows. An organization and its members begin with some existing set of concepts and they encounter change. The members of the organization attempt to explain the change via metaphor. The use of a metaphor evokes a glom of meanings. Each such use of metaphor is a perturbation to the existing self-referencing system (be it an individual, the organization or some holonic part thereof). The perturbations (please notice the plural) caused by the glom or gloms interact in multiple-dimensions with the self-referenced core. This is because the components of the glom each cause their own perturbations in a holonic way. As this series of interactions and resultant emergent behavior self-organizes, "least action" then takes over. The encounter reduces some of the concepts to the status of gloms, and in such a status, the possibility arises for new conceptual understanding to emerge. Such understanding will be influenced by the metaphors available to label the gloms, for in the adjacent meanings implicit in the metaphors is the potential synthesis represented by the new concept. By contrast, gloms will not work well in a system that is dependent upon representations, reductions and causality. In such a world, evoked meanings become reified and are carried across new situated activities. Dissonance from the mismatch - the very attribute of the Mori hypothesis is the likely result.

Ascribed coherence and the use of computers both suggest that rational calculus is applied to the science of meanings (and thus to the affordances which we perceive and to the possibility space we thereby have access to). The Mori hypothesis of the Uncanny Valley reminds us that emotional calculations must also be considered. Intentional blindness is one side effect of the Mori Valley. Emotional evocations of labels such as "evil" are another. There were many warning signs of the housing finance crisis, the increase in political vitriol and even of the Madoff Ponzi scheme. The Mori hypothesis does a good job in explaining why in each case the evidence was not only ignored but denounced.

Managers who face their own Uncanny Valley need to be aware of the risks their own dissonance may be creating.

\section{The Role of the Manager}

Human organizations lacking management seldom thrive. The process of managing is inherently collective. Meaning within organizations is seldom created or imposed by an individual or leader. Leadership instead takes on a facilitating and supportive role - highly skilled and demanding highly developed competencies, but not soloist. The willingness to accept on- 
going and not static truth, the ability to live in process and not need rigid hierarchy are crucial to sense making. Of course one can question how much of the time managing needs sensemaking. One can argue that much of the time managing functions by not seeing problems and by avoiding or repressing change in order to maintain routines. But in a globalized economy of rapid change and short product life cycles management's task to stabilize circumstances and repress change is becoming less and less effective and the need to manage change more and more important. It appears that complex social processes of organizing demanded a cognitive structure that resembled the objects being cognitised. Thus, if business problems are complex then the procedures for narrating and taking activity must also be complex. The appearance or desire for simplicity is a hope that the underlying complexity can be dominated by one or two "controlling" variables. But, that is just hope. Generative, emergent, and collaborate managerial processes do not look hierarchical or offer support for the power and control of a bureaucratic pyramid. The very cognition of management seems to contradict the sociology and organizational principles of traditional managing.

MBA courses teach complexity reduction and business models. The implication is that if the models hold, business is risk free. Follow the models, apply the labels, and success is guaranteed. Consider but one reductionist model, that of: mission, vision, and strategy. Pick a mission, proclaim your vision, and articulate a strategy to get there; success will follow. The popular media has elevated 'vision' to the status of a 'sacred concept' and visionary managers to the status of 'gods'. The vision statement is described by business journals as future focused; a definition of what you want to become in the next three to ten years. Organizations that pursue a vision have vision-based missions and mission-based visions. The mission statement is present focused and defines what you are to do to accomplish your vision. The mission keeps the organization focused on its key customers, products, and services, and helps to evaluate new business opportunities making sure that they fit with the scope of the company's mission.

In their role as "complexity reducers" managers often forget that models can be more than just labels - i.e. that compression models are available too. They accept the fundierung of synecdoche without question. It is after all more efficient to assert the presence of a label and then to "look up" the appropriate behavior or next action based upon the label and not the situation being modeled. This behavior treats context and observation as if were a code and the representation as if it had the power of the compression. Code is the formal name for the use of a token to signify a specific and defined meaning. Codes are reductions. Any reduction's effectiveness is determined not only by the nature of the reductive process but also by the context in which the reduction is employed. Thus, when the goal is efficiency, codes can be very helpful. Morse code allowed for the transmission of a significant amount of information in its day. Codes can be dealt with via look-up tables, statistics and Shannon's information theory. To assume or assert that messages consist of codes is to risk ignoring much of the meaning. Explanations based upon codes (labels, representations) cannot address the situatedness of context dependent actions.

The many self-serving proclamations of uniform and coherent identity found in the mainstream and managerial presses are rarely linked with organizational reality. For example, when Heracleous and Barrett (2001) studied the London insurance market's implementation of electronic trading, they observed that the market's leadership was using the model of 'articulate a mission, a vision, and a strategy, tactics and implementation will follow accordingly' - the metaphor was market as machine and organizations as army. Yet, they found: 


\begin{abstract}
"a view of organizations as constituted of fragmented, competing and, less often, complementary discourses; it is a situation far from the mutually reinforcing discourses found by Thatchenkery and Upadhyaya (1996). We found discursive clashes among stakeholder groups over contested terrain, illustrating both conflict and discursive interpenetration and influence among their discourses. We found fragile agreement and cooperation at the communicative level that was based on potentially conflicting deep structures that could assert themselves in different ways under different contextual conditions. We saw discursive fragmentation, leading to conflicting actions, even within the same stakeholder group sharing the same deep structures, arising because one actor can deem that the group's key goals can be better served by actions that are in conflict with the actions of their own stakeholder group. Lastly, we saw stakeholder groups talking past each other, rather than to each other, because of their almost diametrically opposed discourses, at both the deep structure levels and communicative action levels, and their lack of common ground on which to base a dialogue."
\end{abstract}

The London market leaders were banking on the metaphor of machine for their success. It seems that a better metaphor would have been cacophony.

Actually, it is rare that we all agree on one set of labels and adopt the same model. Often two or more stories emerge to describe a situation. We learn to co-interpret and jointly share circumstances. Stories we have heard and explanations that we have received make circumstances recognizable and sensible. Managers or politicians, or healthcare professionals, or teachers, etcetera, may like to assume that what their audiences hear is what they think they are communicating, but their labels often can be experienced every-which-way. Many like to treat their labels as if context and situation did not exist, and the labels were mono-interpretable. Thus, the nub of the managerial problem: to choose a label is to limit one's possibility space or degrees of freedom, choices and boundaries; and it imposes a set of constraints. If the limitation works --- i.e. leads to the desired results --- in the present environment, then "all is well" for the moment. By imposing limitations, one risks compromising one's potential.

Wing Sun Mak's "counterfeits" satisfied all of the definitions contained in the label counterfeit while their use and intent satisfied none. The police model of what constitutes a counterfeit was vastly different from that understood by those who purchase Chines funeral objects. Liars' loans were perfectly fine so long as housing prices did indeed continue to rise - yet a small number of money managers made considerable sums by acting on the recognition that such a context would not last forever. In America many of the same politicians who refer to one another as evil are all the more likely to actually work together in getting a difficult piece of legislation passed. The explanatory form of the label is, in each of these instances, supplanted by the situated reality of a good story or a better compression.

Another way to say this is that models are partial truths; they partially reflect some aspects of reality. Good models have well defined relationships to reality so that we know how and when to use them. This means that we recognize which aspects of the model are related to which aspects of reality. This is not a piece by piece correspondence, but a behavior by behavior correspondence. Our use of models is clearly not only a property of the model, but a property of our (incomplete) understanding of the relationship between the model and reality. To the extent that managers base projects on labels without a continual cross check with "reality," coherence is threatened. To the extent that managers encourage dialogue about that 
cross check, coherence can be enhanced. But such a dialogue demands the recognition that compressions are not their labels and that ascribed substitutions can be threatening.

\section{Ambiguity versus Uncertainty}

Subtle word differences can matter in a manner similar to explanatory differences. Managers are seldom taught to distinguish between the related concepts of ambiguity and uncertainty. Yet just as they are not taught the meaning of synecdoche, these words and their careful definitions matter. Ambiguity is the simultaneous evocation of multiple possibilities. Ambiguity can be substituted for by probability functions. Uncertainty is something else - it is the lack of certainty evidenced by an unwillingness to act. When we act we act as if we are certain -w e have no such unwillingness. Probability functions cannot provide a willingness to act. This difference is as critical as that between representation and compression and between ascribed and experienced coherence.

Complexity thinking is far more comfortable with the notion of compressions - with the idea that multiple signals are needed for interpretation and for creating enough confidence in context so as to allow both the recognition of affordances and the willingness to act upon them. Complexity would argue that representations overcome uncertainty only in a context of stable and predefined conditions, while compressions allow for the "what-if" questioning and storytelling to overcome uncertainty in a context of change and emergence. Certainty thus becomes the presence of a willingness to act and uncertainty is the absence of that very willingness.

Codes and representations are efficient. And managers like efficiency. One source of the housing bubble and the subsequent financial crisis was the pervasive belief in a code: "housing prices always rise." If the code is accepted as an underlying truth by market participants and regulators alike, there is no one to ask the "what if" questions which otherwise accompany cues. Surely when the general media is discussing such items as "liars loans" (loans made based on false documentation) with no money down, the cues that there is "irrational exuberance" are rampant. But, as we all know only too well, those cues were ignored for the sake of the all-pervasive code. "It does not matter because housing prices only go up."

Much of our language however is presented to us in the context of compressions. Day to day language works because of its usual appearance in a disambiguating context; we are able to choose one of several meanings for a word or sentence because we are in fact guided by the immediate verbal surroundings, the nature of the speech act in which the words are uttered and perceived, the social and historical setting and so on. As speakers, we usually attempt to construct our sentences in such a way as to eradicate any possible ambiguities and, as hearers, we assume single meanings in the sentence we interpret.

Trying to explicate such unclear possibilities pushes us to recognize that it is not any wonder that we prefer predetermined efficiencies as a matter of course? They are tangible, obvious and straightforward to grasp and easy to account for. The MBA cliché of "what cannot be measured does not exist," holds true for codes. Focus on cues may require us to be prepared for something that may or may not appear. In real time situations, managers tend to migrate toward what is easiest and immediately apparent. Yet efficiencies often fail us when embraced as the only means of responding to unexpected occurrence. Openness to cues demands redundancies and reserves, which seem to be the opposite of efficiency. These redundancies and reserves are not just physical, but entail perspectives, ideas and awareness. The emergent 
organization needs an ample supply of stories and narratives to draw upon to help weather the unexpected storm (nasty surprises) and/or to prosper from the unforeseen possibilities (miracles). These stories and narratives resonate back to organization members and provide guidance for their next actions.

While congruence with what has come before makes perfect sense when producing cookies (or bottles, or computers, or airlines), there is (next to) no room for what is not apparent or has not yet have emerged. This is why affordances play such an important role in cuing next possible action, which will not be (exactly) like the last action. Codes rationalize and rigidify affordances, if they do not fetishize and reify them. Cues (try to) reflect the affordances' flexibility, multiplicity and dynamism. Affordances potentially invite us to use the codes we have created and to explore the cues that we are picking up. While affordances can prompt efficient responses, they also can (potentially) invite us to be proactive, creative and resilient. But emergent activity is often more elusive and harder to realize than the efficient brethren. This is especially true when we are attempting to apprehend an emergent possibility that is (partially) hidden from view or may not (yet) be there at all.

Embracing emergence means helping to create the context which affords coherence. When that context is missing coherence can still be imposed from the outside (it is always amazing what fear of force can accomplish temporarily), but the likelihood is that emergence will prove to be transformational in a miracle or nasty surprise sort of way. Ambiguity then surfaces as the simultaneous presence of conflicting meanings. Representations which accept ambiguity may create uncertainty, which then reflected in a lack of willingness to act. That lack of willingness is, in turn, anathema to the manager who turns to still other compressions as vehicles for the embrace of ambiguity as a means of eliminating situational uncertainty. The choice of explanatory form thus has a causal role in determining not only next actions but also the degrees of freedom available for such actions.

\section{Individual's Role in Assigning Meaning}

While codes and similar representations are constrained by pre-established meanings, cues, affordances and similar compressions are free of such constraints. Affordances suggest that meaning is contained from inside one's self. When one encounters a signal, the signal evokes a meaning based on what's going on in the receiver's head and is not based on what the transmitter of the signal intended. We refer to these signals as "cues." The inability to define the environment in which a signal will be interpreted, and the parallel inability to predict affordances are what render cues complex and their study part of qualitative complexity. Cues are thus the label for the emergent meaning which results from an intersection of attendance to environment, situation, history, and cognition, such that semiotic affordance are perceived to allow for action, assignment of cognition, label, or code, or for boundary breaking. Compressions are cued while representations are mapped. Cues tap into experience while codes tap into ascription. Cues are situated and contextual. Codes are ascriptive and conforming to pre-established judgments.

Creativity and innovation depend on access to the degrees of freedom afforded by compressions (cue) and which are denied by representations (code).

Innovation requires the coordinated efforts of many actors to facilitate(1) the recombination of ideas to generate novelty, (2) real-time problem solving, and (3) linkages between present innovation efforts with past experiences and future aspirations...bringing people with disparate perspectives and capabilities 
together during the innovation process can, in turn, create other difficulties. For example, ideas that come from different parts of the organization may remain underused to the extent that people are unable to see their relevance to their own work....unproductive social interactions can exacerbate the uncertainties inherent in innovation processes and increase the chances of generating suboptimal outcomes. (Bartel and Garud, 2009)

Once we create the degrees of freedom both semiotic affordances can be recognized and compressions cued, by telling stories. What matters about a story is what the listeners do with it, not the smile it brings to the face of the teller in its one hundredth reincarnation. Listeners use the images evoked to create meaning ... meaning that goes on to inform actions. When we tell stories and share languaging, the changing context can bring us from raw experience to the possibilities and limits of shared consciousness. Such sharing is the exploration of homologies which underlie the compressions being discussed. Affordances and their import demand an attention to underlying homologies rather than to surface labels. The Russian innovation method TRIZ focuses on just such storytelling.

Stories are among the best tools we have for making sense of our environment and getting comfortable with both what has already occurred and with what is yet to come. Story telling is how we make sense. We tell them to ourselves and to each other. Without them we can only exchange mere words as symbols or icons. If we all had precisely the same set of experiences, the mere sharing of words and icons would be enough. One word would have but one exact meaning. But we all have divergent experiences, and for each of us those experiences are woven together in a multitude of ways. We need stories to make sense of it all.

Memories are stories, stories consist of memories, and both are often expressed through metaphors. The fusion of memory, metaphor, and story enables the creation of meaning around, or to see personal relevance in, a specific affordance or set of affordances. When we are exposed to metaphors, stories, and memories, we don't passively absorb such messages. Instead, we create their own meaning by mixing information from the context with their own memories, other stimuli present at the moment, and the metaphors that come to mind as they think about the attended to affordance. (G. Zaltman, 2003). As William Mitchell put it, "Metaphors do not exist as words in memory, but as networks of abstract understandings that constitute part of our mental imagery." (Mitchell, 1994).

"A story is a narrative told around the formalism of the model. It is neither a deductive consequence of the model nor of the underlying theory. It is, however, inspired by the underlying theory (if there is one). This is because the story takes advantage of the vocabulary of the theory (such as 'gluon') and refers to some of its features (such as its complicated vacuum structure). Using more general terms, the story fits the model in a larger framework (a 'world picture') in a nondeductive way. A story is, therefore, an integral part of a model; it complements the formalism. To put it in a slogan: a model is an (interpreted) formalism plus a story." Hartman (1999)

Stories are not a set of labels. If they were then as the labels get triggered a predefined set of images would be unfolded by the listener. Every listener would hear and construct the same story. Children learn that this is not true when they play "telephone" or "operator." Corporate managers, however, tend to forget this childhood lesson. The children's game illustrates the new things that can emerge as stories are told and retold. The corporate chieftains tend to expect the same meaning to be evoked by their story as they retell it from audience to audience. 
They thus reduce story to representation. The chieftains miss what the children gained. In telling and retelling the same war stories they often fail to ask their listeners about the images the story evoked. What matters about a story is what the listeners do with it, not the smile it brings to the face of the teller in its one hundredth reincarnation. Listeners use the images evoked to create meaning (to build a model/compression which is situated about then present context)... meaning that goes on to inform actions.

John Seely Brown (Brown and Druguid 2000) of PARC Xerox fame likes to say that good stories are emotionally engaging. Stories provide a broader framework that enables us to understand the generalities, or looseness, of ideas. Stories can be embedded in a new context, and the nuggets of knowledge contained in these stories can be applied to a new range of settings. As Orr (1990) puts it, "The key element is the situated production of understanding: through narration, in that the integration of the various facts of the situation is accomplished through a verbal consideration of those facts with a primary criterion of coherence. They do not know where they are going to find the information they need to understand and solve this problem. In their search for inspiration, they tell stories."

Intuition enables us to size up a situation quickly. Mental simulation lets us imagine how a course of action might be carried out. Metaphor draws on experience by suggesting parallels between the current situation and something else we have come across. Storytelling helps us consolidate our experiences to make them available in the future, either to ourselves or to others. The power of a story is that it allows the listener to recreate an experience in his or her mind. Too many details too fine a point on things removes the potency of the listener's imagination. Long before we had computers to run fancy simulation exercises on we used our brains. Long before Disney we had the Brothers Grimm. The power of a good story is in the experience it evokes in its listener. Most stories are set into a context by their tellers. That context reinforces images of place and time. By activating the listener's mental model for a time and place, many details need not be told, and the room is created for the listener's imagination to roam. In effect, the storyteller has carved out a canyon and the listener supplies the river of meaning to run through it.

Each actor coming to the situation has own set of representations and compressions and is forced to react to the assertions of boundaries and indexicals. Individuals have the Mori reaction while algorithms do not.

The context set out by the storyteller will conjure up a new set of "related ideas" in the minds of each listener. Meaning emerges from the combination of what the storyteller supplies and what the listener's mind now adds. Stories suggest new images, combinations of old and new ideas, and allow the listener to place him/herself in a simulacrum of related action. Meaningful stories are not made up of isolated words. They too must evoke deeply held values and images. To offer up isolated words is to evoke a shallow stream of water in a hot desert. Whatever value there is dries up quickly. The empty articulation of representations in the form of jargon which is itself disconnected from the experiences of those who are forced to deal with that articulation can lead to the Mori Valley. The proclamation of a label as being indexical can act to offend the self-identity of those who adhere to a different description or a different context. In metaphorical terms where the successful storyteller has carved the canyon for the compression to run through, the articulator of idle representations has built a canal and the river had other ideas.

Once again the choice of explanatory form can work to expand or restrict the degrees of freedom available to next actions. 


\section{Complexity's demand for dialogue and narrative.}

This chapter would be amiss were it to only raise the problem of incorrect explanatory forms, so we now turn to potential solutions.

Our ultimate device for dealing with complexity and the other is narrative. We use narrative to rise above the local constraints of models. A narrative is not about the reality of a situation. Rather, the point of a story is to lay out in the open what the narrator suggests is important. Narratives are not about being objective, but are instead displays of subjectivity. A narrative is the representation of a compression, which is integrated at a higher level of analysis. Powerful narratives, like great pieces of music, feel as if they were inevitable when they are over, and we seem to agree on that. But note, even in a compelling story, the next line cannot be predicted. It is that feeling of inevitability that endows the great story with its ability to generate commensurate experience amongst independent listeners. (Zellmer, Allen, \& Kesseboehmer, 2007)

Because science as we have defined it in the Western World is supposed to leave out notions of self and of other, its use of models is generally accepted as "objective" and the standard to which other "professions" should aspire. But by definition management includes people and thus includes self and other. Scientists are too well aware that in reality science also includes self and other. The power of affordances and homology has led to many a scientific breakthrough - not due to the intrinsic nature of the subject matter being studied or the data collected but due to the humanness of the scientists who saw adjacent possibles and commonalities of model due to their own experience history and context. Management "science" as it is all too often taught ignores this. Deconstruction studies are often focused on it.

Narratives are important because they are a key tool we all use in dealing with and reducing uncertainty. Having a willingness to act means one is not paralyzed by uncertainty. When we are uncertain we not only struggle to predict what will happen next, but also to understand and to describe why things are currently as they are. (Tenkasi and Boland, 1993). Psychological uncertainty (Berger and Calabrese, 1975) has three components any of which can be paralyzing: doubt about future events (predictive ability), ambiguity about a situation's cause and effect relationships (explanatory ability), and an inability to describe, or to put into words, what is occurring (descriptive ability). Narratives are useful in addressing all three components. Narratives enable people to translate emergent situations that are ambiguous or equivocal so as to promote real-time problem solving (Bartel and Garud, 2009).

what is necessary? The answer is, something that preserves plausibility and coherence, something that is reasonable and memorable, something that embodies past experience and expectations, something which resonates with other people, something that can be constructed retrospectively but also can be used prospectively, something that captures both feeling and thought, .... In short, what is necessary in sense making is a good story (Weick 1995: 60-61).

Since narratives guide us through uncertainty and change, they are critical in how we deal with emergence. "People do not simply tell stories - they enact them" (Pentland 1999.) 
When affordance and homology coincide the amount of effort needed for a coherent response to complexity is reduced. The obverse is also true. But, affordances are not "appropriate" best practices and homologies are not shared labels. In the drive for efficiency such substitutions are all too often proclaimed - at the manager's peril. Managers need to learn that context can be explored for affordances and that the mental models of their stakeholders suppliers, customers, employees, and fellow organization members - can be mined for homologies.

Zellmer et al (2007) note:

"If complex systems are defined, as we and Rosen do, in terms of an incapacity to model them, it is possible to ride out emergence that is characteristic of complexity. One might even come to expect emergence, albeit unpredictable in its details. But we can only do this if we are in a position to recognize the role of the scientist's decisions. Managing for emergence involves changing a point of view. Managing for complex systems requires a meta-level of activity."

That meta-level can be provided if we recognize that the goal is coherence as a setting for action and that the tools for shaping that setting are to be found in affordances, homologies and narrative.

When narratives bring together affordances and homology the possibility for coherent action is vastly increased. Such narratives are by definition compressions and NOT representations. "The sense of coherence expresses a person's inner ability to see existing possibilities around him or herself and make use of the best ones in respect to the demands." (Kalimo et al., 2002.) When, instead labels and judgments are allowed to dominate, while affordances are overlooked, and the cuing of "other" homologies is ignored, the prospect of unanticipated emergence is vastly increased. The fear of the unknown constrains creativity and innovation and in the long-run effectiveness. That fear is implicit when there is an insistence on adherence to representations and a reluctance to explore compressions. Better understandings of affordances, homologies, representations and compressions are thus vital ingredients in the manager's arsenal. Complexity cannot often be managed, but our response to it can be guided -- if we give ourselves the tools.

Narrative can be, and often is, an instrument that provokes active thinking and helps us work through problems. Our need for narrative form is perhaps so strong that we don't really believe something is true unless we can see it as a story. Bringing a collection of events into narrative coherence can be described as a way of normalizing or naturalizing those events. It renders them plausible, allowing one to see how they all "belong." This is a constant theme in the work of historian Hayden White (1980): "The very distinction between real and imaginary events that is basic to modern discussions of both history and fiction presupposes a notion of reality in which "the true" is identified with "the real" only insofar as it can be shown to possess the character of narrativity."

Wherever we look, we seek to grasp what we see. Narrative gives us this understanding. Accordingly, our narrative perception stands ready to be activated in order to give us a frame or context for even the most static and uneventful scenes. And without understanding the narrative, we often feel we don't understand what we see. We cannot find the meaning.

Managerial stories and models can each function as the equivalent of a repairman's tool belt. Only those problems, which can be addressed by the tools at hand, will be noticed, attended to, 
and dealt with. Managers (and management theorists) who have access to the limited perspective of a single tool will see the world in a similarly limited way. "If you give a child a hammer, all the world is a nail." Multiple perspectives are a means of broadening the tool set, allowing for the attention to a wider variety of issues and demands. In short, management theory, management practice, and management science are all situated skills that must adapt to the complex realities swirling about them. Stories are the manager's lenses on the world. MBA's need to tell and listen to stories in addition to models... to focus on relationships and contingencies in addition to money and things... to opt for preparedness over prediction.

"It is important that business leaders see their role as meaning makers. They must pick and choose from the rough materials of reality to construct pictures of great possibilities.... In the choice of words, values, and beliefs, you as a leader craft reality." (Conger ,1991)

To which one might add that in the choice of cue over code, compression over representation, context over indexical, experience over ascription, the manager evokes or limits the degrees of freedom available to the organization being led.

\section{Implications}

Emergence eventually overwhelms whatever complexity reduction and its focus on labels, categories, and simplicity creates. It is the manager's job to prepare for that eventually - to acquire the sagacity which can afford serendipity. The experience of emergence demands some form of coherence so that action can occur and uncertainty be overcome. Ascribed coherence and retrospective judgments are but a temporary salve - dialogue amongst possible narratives, resonance amongst alternative homologies and having the compressions on hand to recognize affordances and the context which may create them are the processes required for ongoing relief. If creativity and innovation are to thrive, they need to be afforded the degrees of freedom in which to thrive. Representations may offer simplicity and efficiency, but they do so at the expense of "space" of the degrees of freedom needed to accommodate emergence and to foster creativity.

Unlike the models in airport business books, rich description in stories and narratives can allow for considerations of complexity, interrelationship, and emotion. A story narrates a past, present, and/or future event. All three contain truths and fictions, thoughts and emotions, and all three overlap. Memories are stories, stories consist of memories, and both are often expressed through metaphors. The fusion of memory, metaphor and story, enables the creation of meaning around, or the seeing of personal relevance in a specific affordance or set of affordances. When we are exposed to metaphors, stories and memories, we create our own meaning by mixing the text with our own memories, perceptions and sensed-affordances (Zaltman, 2003).

Storytelling helps us to consolidate our experiences and to make them available in the future to ourselves and to others. The power of a story is that it allows listeners to recreate experience. Too many details or too much exegesis removes the potency of the imagination. The power of a good story is in the experience it evokes. Most stories are set in a context. That context reinforces the images of place and time. The model of time and place creates order, structure and recognition; many details do not need to be told and room is created for imagination to roam. In effect, the storyteller carves out a canyon for the listener to supply a river of meaning to run through it. Meaning emerges from the combination of what the 
storyteller supplies and what the listener's adds. Stories suggest new images and combinations of old and new ideas, and they allow listeners to place themselves in a simulacrum of related actions. Meaningful stories are not made up of isolated words. They evoke deeply held values and images. To offer up isolated words, is to evoke a shallow stream of water in a hot desert. Whatever value there is dries up quickly.

In their desire to "explain" (and thus to understand causality) managers often construct and interact with narratives built around representations and not around compressions. Such narratives work to reduce uncertainty only while the participants perceive that the label on which the narrative is based is the "best" descriptor for the situation they perceive. When "best" slips to "satisficing", and then to "questioning", the relevance and the resonance of the label- based narrative declines, and coherence declines with it. There are alternatives to making use of labels, categories, and models as the means for establishing coherence and for creating narratives. To address emergence and coherence, managers need a better understanding of how narratives become good "fits" to their situation.

The risk of having too little resilience lies with those who believe that explanation can consist of an assignment to category (as opposed to those who believe that an explanation requires an explication of mechanism). This type of explanation states that if we can identify the category or label to which something or some situation belongs we have sufficiently explained it. If explanation consisted solely of taxonomy such an approach might work. But, category-based explanations provide no guidance for the how something happens and for the what-ifs of change. All that category based explanations can tell you about a "what-if" is whether after the "if" the category assignment still holds true. Fine, when efficiency is the only goal. But, dangerous in a world with emergence.

Thus the error: there is NO single objective account and attempts to claim that there is by means of an identifying label are over-simplifications. Even Lord Ockham of Ockham's Razor fame knew this: "The source of many errors in philosophy is the claim that a distinct signified thing always corresponds to a distinct word in such a way that there are as many distinct entities being signified as there are distinct names or words doing the signifying." (Summula Philosophiae Naturalis III, chap. 7, see also Summa Totus Logicae Bk I, C.51). As Einstein would phrase the error: "Make things as simple as possible, but not simpler."

We now know that the assumptions underlying reductionist approaches to organizational issues are inadequate. The complex nature of managerial issues cannot be discarded and must, therefore, be dealt with in a way that acknowledges their inherent complexity. Disorder, unintended consequences of actions, and turbulence followed by calmer periods is part of the everyday experience of individuals. This dynamism and unpredictability have long fascinated organizational scholars and management consultants alike. Complex realities demand a more complex understanding. The question for scholar and manager alike is to make that understanding cogent for those who need to share it.

With narratives built around compressions, affordances are more easily perceived, opportunities are better exploited (or at least explored), resonance has a better chance of taking hold, and experienced coherence can assert itself in the embrace of emergence. By contrast when emergence is present representations in the form of labels and categories are seldom a good fit. Narratives are important because they are a key tool we all use in dealing with and reducing uncertainty. Having a willingness to act means one is not paralyzed by uncertainty. When we are uncertain we not only struggle to predict what will happen next, but also to understand and to describe why things are currently as they are. (Tenkasi and 
Boland, 1993). Narratives enable people to translate emergent situations that are ambiguous or equivocal so as to promote real-time problem solving (Bartel and Garud, 2009).

By restricting ourselves to a set of representations, we predetermine what might be learned, which will limit the options that appear to be open to us. Stopping here is what acts to stifle creativity and ultimately to interfere with effectiveness. What is critical is that the interpretive and retelling efforts NOT stop when the representation gets assigned. To stop at this point is to ignore dialogue and revert to the ascribed coherence and retrospective judgments of identity where the label is the explanation. Instead the goal is to keep dialoguing so that homologies of mechanism and what-if effects can be exposed to articulation, pondered about, and used to shape an ongoing narrative. That narrative serves as the compression and is the alternative to representation. With such compressions, affordances are more easily perceived, opportunities are better exploited (or at least explored), resonance has a better chance of taking hold, and experienced coherence can assert itself in the embrace of emergence.

Consider, for example, the rise of the smartphone. At the start of the past decade, consumers could confidently leave their homes with just their wallets, keys and mobile phones; by 2010 they often felt the need to clutter their briefcases with iPods, iPhones, BlackBerrys, netbooks, e-book readers and other gadgets. In 2008, mobile phone ownership exceeded four billion users -- which equated to nearly 60 percent of the world's then population. In 2010 it was predicted that by 2013, more than one billion people will own a smartphone. The smartphone segment consists of a group of highly disruptive converged devices, with programmable OS, continually improving functionality, wireless networking capabilities and a younger reach that will hinder the growth of dedicated devices. Inherent limitations for the smartphone are screen size, lack of full size keyboard, storage shortfalls and battery life. Features like optical zoom and image stabilization in cameras or embedded maps in personal navigation devices are seen as key value-add differentiators, and still drive consumers to make that purchase. Nearly all observers suggest that the continued rise of the smartphone will have a major impact on the handheld device landscape.

Managers discussing this market can make use of the many studies which label categorize and otherwise segment the marketplace. They can make use of $2 \times 2$ matrices such as the one below to plot strategy and suggest next courses of action:

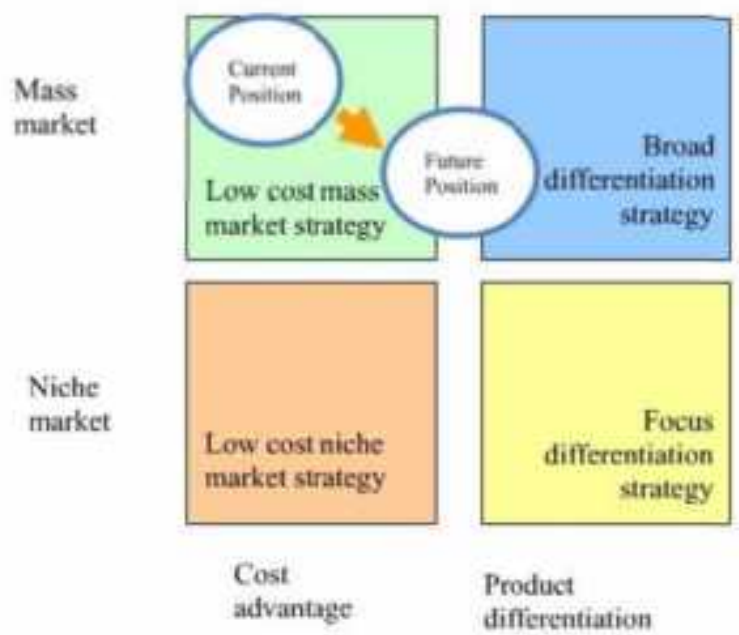

Figure 3: 2X2 Matrix of the Smartphone Market 
They could make use of the labels of users or of the phones themselves.

One such study suggested that there were 7 consumer segments to be pursued (and an eighth enterprise segment):

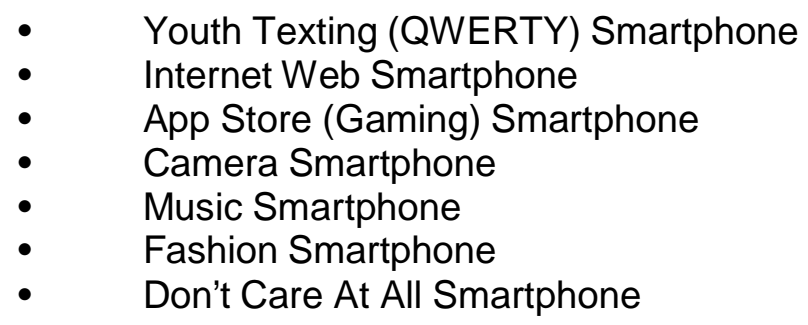

Using the ascribed coherence, rules based, category dominated MBA approach, the managers would pick their segment apply the strategy matrix above perhaps do a Porter SWOT analysis and be done.

By contrast a manager who followed the dialoging approach would seek to understand relationships. As this manager develops narratives around the suggested relationships, product/service strategies and differentiation become a natural output. The stories (youth fashionista who takes many pictures of clothes and their wearers, sends those pictures to friends and her computer, and talks on phone while snapping) may suggest affordances or the opportunity gap for an affordance (use automatic gps location for the photos to display nearest store with similar merchandise). The what-if and mechanisms of these compressions are far more resilient than the perspective restricted notions of category and label. The dialogue around the narratives captures and compresses the complexity of the situation and the resultant experienced emergent coherence while the restrictions of the category approach can only measure adherence to a pre-defined ascribed coherence or its lack. So too with any other product or service which addresses multiple ever-changing niches or otherwise must deal with emergence ... narratives and dialogue can embody the very complexity which labels and categories attempt to discard.

Rosen (1985) argued that complexity was revealed by items, events, situations which could not be represented EXCEPT by more than one model. (And the presence of more than on model is a compression not a representation.) To simplify such complex items was to ignore many of their traits. Yet, the ignored traits may be the very ones which matter in the context at hand. Former Supreme Court Justice David Souter made a similar point in a 2010 speech at Harvard:

The explicit terms of the Constitution, in other words, can create a conflict of approved values, and the explicit terms of the Constitution do not resolve that conflict when it arises. A choice may have to be made, not because language is vague but because the Constitution embodies the desire of the American people, like most people, to have things both ways. We want order and security, and we want liberty. And we want not only liberty but equality as well. These paired desires of ours can clash, and when they do a court is forced to choose between them, between one constitutional good and another one. The court has to decide which of our approved desires has the better claim, right here, right now, and a court has to do more than read fairly when it makes this kind of choice. 
Instead of a single objective account we must learn to become comfortable with multiple, partial, subjective and even conflicting accounts. This is the role of dialogue and of compressions. The goal is to discover explanations of how and what-if which can then be used to prepare for the emergent future and for unfolding affordances.

Single accounts, ascribed labels, adherence to categories and to coding, are all in accordance with the acceptance of context as being pre-given and unchangeable. There is an alternative. We can work to alter the context, to shape it, to help influence what affordances it presents and what narratives it affords.

To do this we need to stop making lists of labels and categories. We need to stop drawing the two-by two matrices of which MBA's are so fond. Instead we need to outline the ingredients for dialogue surrounding the situation, idea, or context we seek to address. We can do this by making use of the dialogic square. We can do this by emphasizing the need to consider the DIS-similarities evoked by analogies and metaphors. WE can do this by remembering that representations are NOT enough, that we need to be making use of models which involve compressions if we expect to capture enough of the complexity around us so as to preserve our resilience.

Efficiency can be the enemy of resilience. A drive for simplicity can be the enemy of awareness. A quest for checklists, labels, rules and categories can be the enemy of tomorrow's possibilities. In the quest to limit possibility space itself lies yet another avenue for complex causation.

Thus our lessons from this chapter: Explanation can take the form of category or of mechanism. Category based explanation may be efficient but they are not resilient. Resilience requires: narratives not labels, mechanisms not categories, a focus on experience and not on labels and a need to be aware of when representations work and when they fail. Managers need to become aware of the complex role of both representations and compressions in defining the possibility space, in allowing for the overt recognition of affordances, and in challenging the experience of coherence as life itself unfolds. The choice of explanatory form has a causal role bigger than they might assume.

\section{Glossary of Terms}

Ascription: the act of labeling

Coherence: holding together as one and in so doing "making sense"

Compression: a reduction of data in the form of a simplified story or model

Emergence: the arising of something new in state or phase which was not predicted from the prior state of affairs

Fundierung: the relationship which governs our use of something for an action without our paying particular attention to the something being used (our ignorance of the pen while we are using it to write) 
Homology: a relationship between two items which can be modeled by the same or similar compression

Indexical: a term held to stand for some other where the reference is defined by the context of the utterance

Model: a relationship between an abstract compression and a real world process which allows for predictions regarding the abstract compression to be mapped into the "real world" and vice versa

Representation: a label or category assignment where the symbolic token is used to stand for that which is being represented

Synecdoche: a part of speech where a part is used to stand for the whole

\section{References}

Bartel, C. and Garud, R. (2009). The Role of Narratives in Sustaining Organizational Innovation, Organization Science 20: 107-117.

Berger, C., \& Calabrese, R. (1975). Some exploration in initial interactions and beyond: Toward a developmental theory of interpersonal communication. Human Communication Research, 1, 99-112.

Berman, D. (2012). So, What's Your Algorithm?, Wall Street Journal, January 4, 2012.

Brown, J. S and Duguid, P. (2000). The Social Life of Information, Boston, MA: Harvard Business School Press.

Bryant, D. (2006) http://www.arclight.net/ pdb/nonfiction/uncanny-valley.html

Conger, J. (1991). "Inspiring Others, The Language Of Leadership," Academy Of Management Executive, 5(1): 31-45.

Gibson, J.J. (1977) The theory of affordances. In R. Shaw \& J. Bransford (eds.), Perceiving, Acting and Knowing. Hillsdale, NJ: Erlbaum.

Gibson, J.J. (1979). The Ecological Approach to Visual Perception. Boston: Houghton Mifflin.

Hartman, G. (1999) Saving The Text: Literature, Derrida, Philosophy, Baltimore, Johns Hopkins University Press

Heracleous, L. and Barrett, M. (2001). "Organizational change as discourse: Communicative actions and deep structures in the context of IT Implementation," Academy of Management Journal, 44(4): 755-778.

Hofstadler, D. (1995). Fluid Concepts and Creative Analogies. New York, Basic Books.

Husserl, E. (1900) Logical Investigations, trans. J. N. Findlay, London: Routledge 1973.

Kahneman, D. (2011). Thinking, Fast and Slow, New York, Farrar, Straus and Giroux. 
Kalimo, R., Pahkin, K. \& Mutanen, P. (2002). Work and personal resources as longterm predictors of well-being. Stress and Health, 18, 5, pp. 227-234.

Kauffman, S. (2002). Investigations, Oxford University Press.

Kuhn, T. (1962). The Structure of Scientific Revolutions. University of Chicago Press, Chicago.

Letiche, H. \& Lissack, M. (with Schultz, R.) (2011) Miracles and Nasty Surprises: Coherence, Emergence, Complexity and Organization, forthcoming

Lissack, M.(2009). Complexity is more than a Label: A look at Affordances and Homologies,Keynote Speech at The 2nd International Multi-Conference on Engineering and Technological Innovation: IMETI 2009 ,July 10th - 13th, 2009 - Orlando, Florida, USA

Lissack, M. \& Richardson, K. (2001) "When Modeling Social Systems, Models - the Modeled: Reacting to Wolfram's A New Kind of Science", Emergence, vol. 3, no. 4, pp. 95-111.

Lissack, M. \& Richardson, K., (2003), "Models without morals: towards the ethical use of business models", Emergence, Vol.5, No. 2, pp 72-102

Lissack, M., and J. Roos, (1999), The Next Common Sense: Mastering Corporate Complexity through Coherence, Nicholas Brealey Publishing, London

McGrenere, J., \& Ho, W. (2000). Affordances: Clarifying and evolving a concept. Proceedings of. Graphics Interface 2000, Montreal, QC

Mitchell W (1994) The Reconfigured Eye: Visual Truth In The Post-Photographic Era Mit Press

Mori, M (1970). Bukimi no tani The uncanny valley (K. F. MacDorman \& T. Minato, Trans.). Energy, 7(4), 33-35. (Originally in Japanese)

Mori, M (1982) The Buddha in the Robot. Charles E. Tuttle Co., 1982; ISBN 4333010020.

Orr, J. (1990). "Sharing Knowledge, Celebrating Identity, Community Memory in A Service Culture," in Middleton, D. and Edwards, D. (eds.), Collective Remembering. London, Sage Publications, pp. 169-189....

Pentland, B. (1999). Building process theory with narrative: From description to explanation. Academy of Management Review 24: 711-724.

Rosen, R. (1985). Anticipatory Systems. Pergamon, London.

Singer J. and Kilgannon C. (2011). "Yes, He Sold Fakes. They Are Supposed to Be Fake." New York Times, August 24, 2011

Souter, D. (2010) Speech at Harvard University

Srivasta, S. and Barrett, F. (1988). "The Transforming Nature of Metaphors in Group Development: A Study in Group Theory," Human Relations, 41: 31-64. 
Star SL \& Griesemer JR (1989). "Institutional Ecology, 'Translations' and Boundary Objects: Amateurs and Professionals in Berkeley's Museum of Vertebrate Zoology, 1907-39". Social Studies of Science 19 (3): 387-420

Tenkasi, R. and Boland, R. (1993). Locating Meaning Making in Organizational Learning: The Narrative Basis of Cognition. In R. W. Woodman and W. A. Pasmore (Eds.), Research in Organizational Change and Development, Vol. 7, Greenwich CT: JAI Press. Pp. 77-103.

Thagard, P. (1992). Conceptual Revolutions, Princeton U Press

Thagard, P. (2000). Coherence in Thought and Action, MIT Press.

Thatchenkery, T., \& Upadhyaya, P. (1996). Organizations as a play of multiple and dynamic discourses: An example from a global social change organization. In Boje, D., Gephart, R., and Thatchenkery, T. (Eds.). Postmodern Management and Organization Theory. Newbury Park, CA: Sage.

Vygotsky, Lev Semenovich. (1962). Thought and language. Edited and translated by Eugenia Hanfmann and Gertrude Vakar. Cambridge, MA, NY: MIT Press; John Wiley.

Weick, K. (1995). Sensemaking in organizations. Thousand Oaks, CA: Sage Publications, Inc.

White, H. (1980). "The Value of Narrativity in the Representation of Reality", Critical Inquiry, Vol. 7, No. 1, On Narrative (Autumn), pp. 5-27.

Zaltman, G. (2003) How Customers Think: Essential Insights Into The Mind Of The Market. Boston: Harvard Business School Press

Zellmer AJ, Allen TFH, Kesseboehmer K. (2007). The nature of ecological complexity: A protocol for building the narrative. Ecological Complexity 3: 171-182. 